\title{
Correlation between Coating Adhesion and Damage Threshold: Simple Method of Reliability Assessment for Optoelectronic Applications
}

\author{
Jongwoo Park ${ }^{1}$, Dong-Soo Shin ${ }^{2}$ \\ ${ }^{1}$ Samsung Electronics, System LSI Business, Yongin, Korea \\ ${ }^{2}$ Department of Applied Physics, Hanyang University, ERICA Campus, Ansan, Korea \\ Email: $\underline{\text { dshin@hanyang.ac.kr }}$
}

Received 25 February 2015; accepted 6 April 2015; published 9 April 2015

Copyright (C) 2015 by authors and Scientific Research Publishing Inc.

This work is licensed under the Creative Commons Attribution International License (CC BY). http://creativecommons.org/licenses/by/4.0/

\section{(c) (i) Open Access}

\begin{abstract}
It is demonstrated that inherent coating adhesion and damage threshold are correlated for $\mathrm{Ta}_{2} \mathrm{O}_{5}$ and $\mathrm{HfO}_{2}$ coatings widely used in optoelectronic devices. By utilizing a newly proposed 1-h boiling water test combined with the optical aging under high-power laser irradiation, we show that an optical coating that survives the 1-h boiling water test withstands the damage threshold, ensuring the field service life even in harsh environments. Besides the standard evaluation methods, which may have limitations for applications required in harsh environments, the 1-h boiling water test can serve as an alternative method of reliability assessment for optical coatings. A heuristics herein can be used as a gating item for qualification of optical coatings for various applications.
\end{abstract}

\section{Keywords}

Optical Coating, Boiling Water Test, Damage Threshold, Adhesion, High-Power Laser

\section{Introduction}

For optoelectronic devices such as complementary metal-oxide-semiconductor (CMOS) image sensors and highpower lasers, physical properties of optical coatings are very important not only to achieve a designated device performance but also to secure a reliable field service life. Steadfast demands for the device performance in terms of resolution and power have driven improvements of optical coatings from the reliability perspective. In the case of high-power-laser applications, the laser-induced damage of an optical coating is a critical factor to 
the failure of external-cavity laser modules. In the literature, two main mechanisms are listed to be responsible for the laser-induced damage of an optical coating: dielectric breakdown and thermal absorption [1] [2]. It is also known that impurities significantly affect the mechanical and optical properties of a coating and cause rapid radiation absorption leading to the laser-induced damage [3].

Nevertheless, a reliability metric of an optical coating still relies on a legacy standard procedure extracted from the product-level qualification. Furthermore, the phenomenon of the laser-induced damage has not yet been fully established in relation to the inherent adhesion strength of the coating. In particular, a simple test methodology that can yield a fast turnaround result without a specified test requirement as well as a complicated experimental setup has not yet been available for the optical coatings used in optoelectronic devices. In this study, we aim to establish the inherent correlation between the adhesion strength and the laser-induced damage threshold of optical coatings. We first show that the existing reliability assessment method cannot effectively screen out intrinsically weak optical coatings for high-power laser applications. Then, by proposing a simple new test method, namely, a boiling-water test, we provide a practical test methodology that can be added into reliability metrics for qualification of optical coatings that require very strong adhesion such as in high-power lasers.

\section{Optical-Coating Evaluation by Standard Procedures}

For investigation, we utilized tantalum oxide $\left(\mathrm{Ta}_{2} \mathrm{O}_{5}\right)$ and hafnium oxide $\left(\mathrm{HfO}_{2}\right)$ optical coatings prepared by evaporation and oxidation with reactive deposition or ion beam bombardment [4] [5]. Optical coatings were visually inspected with optical microscopy after deposition. To prevent secondary surface contaminations, care had been taken in handling optical components for further assembly necessary for building up the laser modules.

We first evaluated the optical coatings with the standard reliability assessment as shown in Table 1 to qualify the optical coatings. Both coatings of $\mathrm{Ta}_{2} \mathrm{O}_{5}$ and $\mathrm{HfO}_{2}$ were found to pass this standard reliability assessment. As a method to establish the adhesion strength of optical coatings, the tape and shear tests were employed referring to the MIL specs [6] [7]. The optical coatings herein secured intrinsic film reliability throughout tape and abrasion tests after $24 \mathrm{~h}$ at $49^{\circ} \mathrm{C}$ and with $\geq 95 \%$ relative humidity.

However, when the $\mathrm{Ta}_{2} \mathrm{O}_{5}$ films were used as optical coatings in the actual high-power pump laser modules with an external cavity, the output power of the module tended to deteriorate with increasing lasing time. Therefore, the existing standard methodology of reliability assessment has a severe limitation for a component level, incapable of screening inherently weak features from the reliability perspective. Despite meticulous efforts, the effectiveness and screenability of the MIL standard for an optical-coating is found to be doubtful in our case.

Figure 1 is given to explain the behaviors of output power degradation of high-power pump laser modules with $\mathrm{Ta}_{2} \mathrm{O}_{5}$ films. The laser modules lased at $980 \mathrm{~nm}$ in continuous-wave (CW) mode at an injection current of $700 \mathrm{~mA}$. The temperature of the module was controlled by a thermoelectric cooler kept at $25^{\circ} \mathrm{C}$. As shown in Figure 1, two different failure mechanisms, namely, the laser failure and the $\mathrm{Ta}_{2} \mathrm{O}_{5}$ film degradation caused by the high-power laser can be noticeably differentiated. Rapid power deterioration in the high-power laser (represented by triangles) is attributed to the formation of the catastrophic optical mirror damage associated with the facet coating of the pump laser [8] [9]. On the other hand, the $\mathrm{Ta}_{2} \mathrm{O}_{5}$ optical coating used in the high-power laser module results in a gradual degradation in the output power with increasing aging time (represented by circles). After $2500 \mathrm{~h}$ of aging, approximately $25 \%$ of the output power has diminished. If both the laser and the

Table 1. Reliability qualification metrics for an optical coating.

\begin{tabular}{cc}
\hline Test item & Stress condition \\
\hline High temperature & $150^{\circ} \mathrm{C}$ for $1000 \mathrm{~h}$ \\
Low temperature & $-40^{\circ} \mathrm{C}$ for $1000 \mathrm{~h}$ \\
Unbiased HAST & $85^{\circ} \mathrm{C} / 85 \%$ relative humidity for $1000 \mathrm{~h}$ \\
Thermal shock & $-40^{\circ} \mathrm{C}$ to $85^{\circ} \mathrm{C}$ \\
Adhesion & Tape peeling off \\
Chemical resistance & Acetone cleaning \\
\hline
\end{tabular}


optical coating were inert and not damaged, the slope of the output power would level off even with increasing aging time, which would suggest that each component such as the laser or the optical coating is reliable and robust to meet the reliability specification.

Figure 2 exhibits an optical micrograph of the laser-induced damage of the optical coating resulting from the aging driven by the high-power laser. A large blistering of $\mathrm{Ta}_{2} \mathrm{O}_{5}$ shown in Figure 2 is sufficient to hinder the optical power in the active path. Subsequently, the investigation is further focused on the degradation of an optical coating induced by the high-power laser.

\section{Optical Aging Test of the Thin Film}

To facilitate the optical microscopy and testing of the damage threshold of the optical coating, a $\mathrm{Ta}_{2} \mathrm{O}_{5}$ film deposited on an Er-doped glass was chosen. A simple aging test driven by a high-power CW laser was set up and employed to appraise the reliability of an optical coating. As an active power source, a 980-nm high-power laser was operated at $25^{\circ} \mathrm{C}$ at a current level of $700 \mathrm{~mA}$, and the corresponding output power ( $\left.\sim 530 \mathrm{~mW}\right)$ through the optical coating was measured by a detector as an indicator to monitor the degradation process in the optical

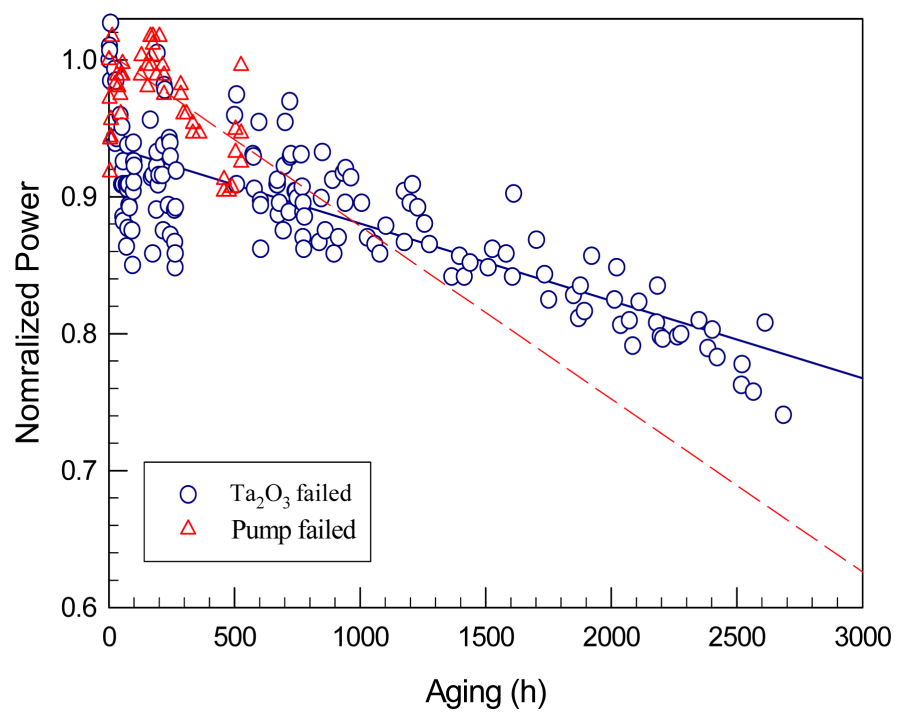

Figure 1. Behaviors of the optical power associated with i) degradation of the high-power pump laser and ii) degradation of the $\mathrm{Ta}_{2} \mathrm{O}_{5}$ coating induced by the high-power laser (each failed after $500 \mathrm{~h}$ and $2500 \mathrm{~h}$ of aging test, respectively).

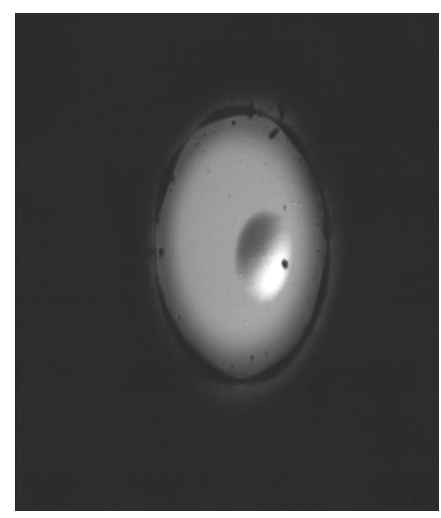

Figure 2. Optical micrograph $(50 \times)$ of the laser-induced damage threshold in the $\mathrm{Ta}_{2} \mathrm{O}_{5}$ coating responsible for the decrease in the output power shown in Figure 1. 


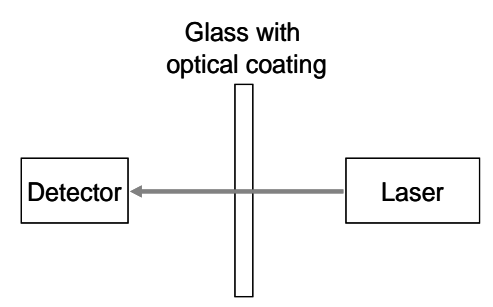

Figure 3. Schematic diagram of the simple aging test on the optical coatings, driven by a high-power laser.
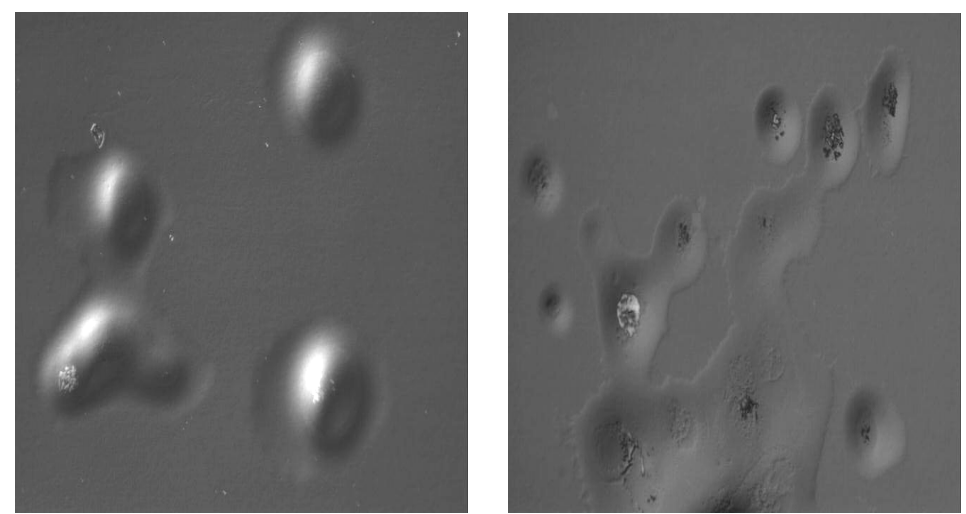

Figure 4. Laser-induced damage of $\mathrm{Ta}_{2} \mathrm{O}_{5}$ showing blistering after $1000 \mathrm{~h}$ of aging under the magnification of $100 \times$.

coating. A schematic diagram of the optical testing is shown in Figure 3. This aging test continued up to $5000 \mathrm{~h}$ under ambient conditions.

As shown in Figure 4, the simple optical aging test also induced the coating damage in the $\mathrm{Ta}_{2} \mathrm{O}_{5}$ coating similar to what is shown in Figure 2, which resulted in either abrupt or gradual deterioration in the output power. After $1000 \mathrm{~h}$ of aging, a nucleation of the damage threshold formed on the coated glass on which the high-power laser was focused during the simple aging test. It was found that blistering on the optical coating continued to grow and expanded and then later coalesced with increasing aging time.

\section{Newly Proposed Reliability Assessment Method}

To evaluate inherent adhesion strength of coatings used especially in high-power laser applications, a new assessment method, namely, the 1-h boiling water test was adopted rather than the typical adhesion tests of tape and/or shear [6] [7] for its simplicity as well as fast turnaround results. One might argue that such a test would not be a quantitative method for the optical-coating evaluation and would be much severer than what is of necessity. However, both the tape and 1-h boiling water tests are difficult to provide quantitative and measurable adhesion strength of the optical coating. Moreover, as we have seen previously, an optical coating that had passed the MIL-based assessments turned out to be vulnerable and compromised to the damage induced by a high-power laser. This justifies a new test method that can overcome the limitation of the existing one particularly for this specific application.

For the boiling water test, we used the $\mathrm{HfO}_{2}$ coating as well as the $\mathrm{Ta}_{2} \mathrm{O}_{5}$ coating to check the difference between the coatings and the viability of the testing method. Before and after the 1-h boiling water test, the coating surface was carefully captured with optical and electron microscopies. The results from the 1-h boiling water test and the simple optical aging test were compared to understand the correlation between the inherent adhesion strength and the laser-induced damage threshold.

Figure 5 shows optical micrographs of the $\mathrm{Ta}_{2} \mathrm{O}_{5}$ and ion-beam assisted $\mathrm{HfO}_{2}$ films deposited on an Er-doped glasses after they were dipped into the boiling water for $1 \mathrm{~h}$. It is seen that severe blisters appear on the $\mathrm{Ta}_{2} \mathrm{O}_{5}$ film, while the $\mathrm{HfO}_{2}$ film seems more stable and inert to the 1-h boiling water test. It is rather surprising that the $\mathrm{HfO}_{2}$ film can endure such a harsh test of boiling water. This implies that the $\mathrm{HfO}_{2}$ film has an adhesion strength 
higher than that of the $\mathrm{Ta}_{2} \mathrm{O}_{5}$ film.

In order to validate that the $\mathrm{HfO}_{2}$ film is more reliable than the $\mathrm{Ta}_{2} \mathrm{O}_{5}$ film as obtained from the 1-h boiling water test, optical glasses coated with the $\mathrm{Ta}_{2} \mathrm{O}_{5}$ and $\mathrm{HfO}_{2}$ films were prepared in the same fashion described previously and then directly exposed to the high-power laser. The output power of the laser was monitored as a function of stress time as described in Figure 3.

Figure 6 shows the behaviors of the output power for $\mathrm{Ta}_{2} \mathrm{O}_{5}$ - and $\mathrm{HfO}_{2}$-coated optical pieces. Obviously, the $\mathrm{Ta}_{2} \mathrm{O}_{5}$ coating (open circles) is seen to degrade gradually after $1000 \mathrm{~h}$. On the other hand, $\mathrm{HfO}_{2}$ (filled circles) reveals a stable output power even after $3500 \mathrm{~h}$ of stressing. An optical microscopy on $\mathrm{Ta}_{2} \mathrm{O}_{5}$ exhibits blistering as previously discussed. Note that the damage threshold for $\mathrm{Ta}_{2} \mathrm{O}_{5}$ and $\mathrm{HfO}_{2}$ is $8-10 \mathrm{~J} / \mathrm{cm}^{2}$ and $30 \mathrm{~J} / \mathrm{cm}^{2}$, respectively. In the literature, the coating failure has been investigated with respect to the damage threshold [10] [11]. Overall, the results shown in Figure 6 reveal a good agreement with the 1-h boiling water test, supporting an inherent correlation between the adhesion strength and the laser-induced damage threshold for optical coatings. Therefore, the 1-h boiling water test does provide a fast turnaround result that can substantially help both the coating and the high-power-laser industries from the reliability perspective, leading to cost-effective production.

From the results examined so far, it can be concluded that the higher adhesion strength will provide better immunity against the laser-induced damage. Also, the 1-h boiling water test incorporated with the simple optical

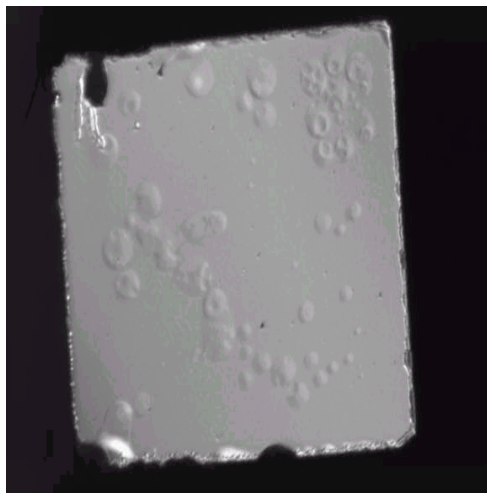

(a)

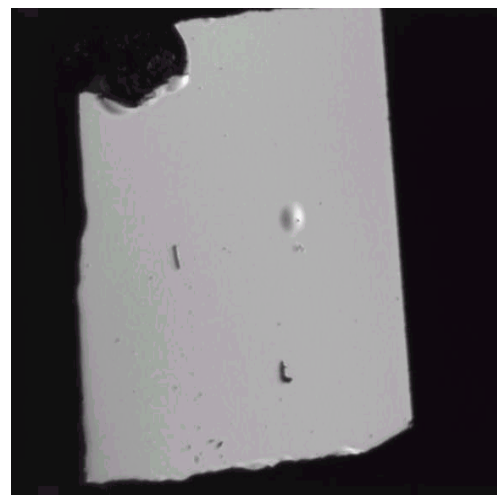

(b)

Figure 5. Optical micrographs of the blistering induced by a 1-h boiling water test: (a) $\mathrm{Ta}_{2} \mathrm{O}_{5}$ and (b) $\mathrm{HfO}_{2}$ under the magnification of $100 \times$.

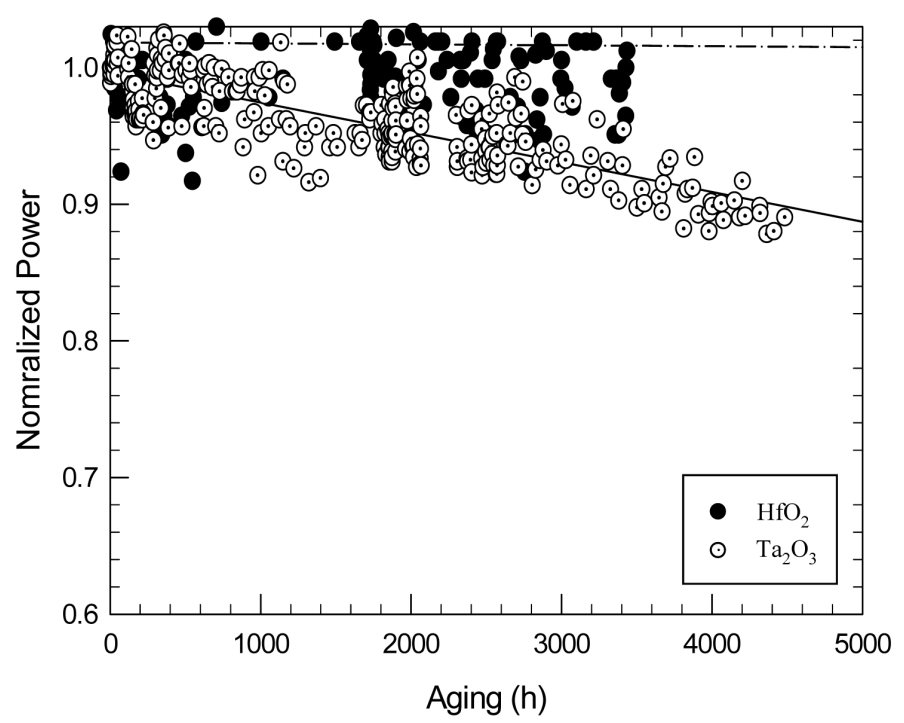

Figure 6. Results of the aging test on the optical coatings with a high-power laser operated at $25^{\circ} \mathrm{C}$ with an injection current of $700 \mathrm{~mA}$. 
aging test can be a very useful alternative methodology that can effectively screen out the inherently weak optical coating for reliability qualification. These results suggest that both the damage threshold and the adhesion strength of an optical coating need to be taken into account for selection of an optical coating in optoelectronic devices.

\section{Conclusion}

As an alternative method to the existing reliability evaluations, we have demonstrated that the simple optical aging and the 1-h boiling water test are capable of screening the inherently weak optical coating that may be compromised under harsh applications. The results observed from the microscopy after the 1-h boiling water test are in good agreement with the optical aging test driven by a high-power laser, validating inherent correlation between the adhesion strength and the laser-induced damage threshold for high-power-laser applications. This fact suggests that both the damage threshold and the adhesion strength of an optical coating need to be taken into account for the selection of an optical coating in optoelectronic devices. It is envisaged that such a fast test methodology proposed herein will substantially help the coating and laser industries, leading to cost-effective production with reliable materials and components.

\section{References}

[1] Gallais, L., Capoulade, J., Wagner, F., Natoli, J.Y. and Commandré, M. (2007) Analysis of Material Modifications Induced during Laser Damage in $\mathrm{SiO}_{2}$ Thin Films. Optics Communications, 272, 221-226. http://dx.doi.org/10.1016/j.optcom.2006.11.025

[2] Papernov, S. and Schmid, A.W. (2005) Two Mechanisms of Crater Formation in Ultraviolet-Pulsed-Laser Irradiated $\mathrm{SiO}_{2}$ Thin Films with Artificial Defects. Journal of Applied Physics, 97, Article ID: 114906. http://dx.doi.org/10.1063/1.1924878

[3] Wu, S., Tian, G., Xia, Z., Shao, J. and Fan, Z. (2006) Influence of Negative Ion Element Impurities on Laser Induced Damage Threshold of $\mathrm{HfO}_{2}$ Thin Film. Applied Surface Science, 253, 1111-1115. http://dx.doi.org/10.1016/j.apsusc.2006.01.055

[4] Kruschwitz, J.D.T. and Pawlewicz, W.T. (1997) Optical and Durability Properties of Infrared Transmitting Thin Films. Applied Optics, 36, 2157-2159. http://dx.doi.org/10.1364/AO.36.002157

[5] Al-Kuhaili, M.F. (2004) Optical Properties of Hafnium Oxide Thin Films and Their Application in Energy-Efficient Windows. Optical Materials, 27, 383-387. http://dx.doi.org/10.1016/j.optmat.2004.04.014

[6] Test Method Standard Microcircuit, MIL-C-48497A, 1980.

[7] Test Method Standard Microcircuit, MIL-STD-810C, 1996.

[8] Fritz, W.J. (1990) Analysis of Rapid Degradation in High-Power (AlGa)As Laser Diodes. IEEE Journal of Quantum Electronics, 26, 68-74. http://dx.doi.org/10.1109/3.44918

[9] Park, J. and Shin, D.-S. (2004) Package-Induced Catastrophic Mirror Damage of 980-nm GaAs High-Power Laser. Materials Chemistry and Physics, 88, 410-416. http://dx.doi.org/10.1016/j.matchemphys.2004.08.012

[10] Zhang, D., Fan, S., Zhao, Y., Gao, W., Shao, J., Fan, R., Wang, Y. and Fan, Z. (2005) High Laser-Induced Damage Threshold $\mathrm{HfO}_{2}$ Films Prepared by Ion-Assisted Electron Beam Evaporation. Applied Surface Science, 243, $232-237$. http://dx.doi.org/10.1016/j.apsusc.2004.09.083

[11] Akhtar, S.M.J., Ristau, D., Ebert, J. and Welling, H. (2007) High Damage Threshold Single and Double Layer Antireflection (AR) Coatings for Nd:YAG Laser: Conventional Systems. Journal of Optoelectronics and Advanced Materials, 9, 2391-2399. 